NASZA DERMATOLOGIA Onlin OUR DERMATOLOGY Online

Source of Support: Nil

Competing Interests: None

\section{SUBCUTANEOUS PANNICULITIS- LIKE T-CELL LYMPHOMA: REPORT OF TWO CASES}

\author{
Jyoti Ramnath Kini ${ }^{1}$, Ancy Susan John ${ }^{1}$, Hema Kini ${ }^{1}$, \\ Flora Dorothy Lobo ${ }^{1}$, Pramod Kumar², Krishna Prasad ${ }^{3}$
}

${ }^{1}$ Department of Pathology, Kasturba Medical College, Mangalore, Manipal

University, Manipal, Karnataka, India

${ }^{2}$ Department of Dermatology, Kasturba Medical College, Mangalore, Manipal

University, Manipal, Karnataka, India

${ }^{3}$ Department of Oncology, Kasturba Medical College, Mangalore, Manipal University, Manipal, Karnataka, India

Corresponding author: Ass. Prof. Jyoti Ramnath Kini

kinijyoti@gmail.com

\begin{abstract}
Subcutaneous panniculitis-like T-cell lymphoma is a distinct variant of cutaneous T-cell lymphoma, characterized by primary involvement of the subcutaneous fat in a manner mimicking panniculitis. It accounts for less than one percent of all non Hodgkin lymphoma. We describe two such patients who presented with cutaneous nodules. A 28 year old male presented with a one and a half month history of multiple subcutaneous nodules over the thighs, abdominal wall and chest. A clinical diagnosis of panniculitis was made. An excision biopsy of one the nodules was performed and the histopathology revealed subcutaneous panniculitis-like T-cell lymphoma. The other patient was a 44 year old male who underwent excision of a subcutaneous mass in the right thigh and on histopathological examination a diagnosis of subcutaneous panniculitis-like T-cell lymphoma was made. The patients received one cycle of CHOP (cyclophoshamide, vincristine, doxorubicin and prednisolone) regimen, followed by systemic steroids and were advised follow up.
\end{abstract}

Key words: Subcutaneous Panniculitis-like T-cell Lymphoma; panniculitis; cutaneous T-cell lymphoma; non Hodgkin lymphoma

\section{Introduction}

Subcutaneous panniculitis-like T-cell lymphoma (SPTCL) originally described by Gonzalez et al is a primary cutaneous lymphoma (PCL) characterized by an aggressive clinical course and hypodermal involvement [1]. The annual incidence of cutaneous lymphoma is estimated to be from 0.5 to 1 per 1 , 00,000 persons per year.[2] SPTCL is a rare extranodal non Hodgkin lymphoma (NHL) accounting for less than one percent of all NHL [1-5] and resembles certain benign panniculitis like lupus panniculitis and erythema nodosum clinically and histologically.

We present the clinicopathological features of two such cases and discuss the differential diagnosis, immunohistochemical and molecular features of SPTCL

\section{Case Report}

Case 1

A 28 year old male presented with a history of high grade fever followed by eruption of multiple swellings over the thighs, chest and abdominal wall, of one and a half months duration. On examination, a number of firm to hard, indurated, $1-5 \mathrm{~cm}$ sized, cutaneous nodules and plaques with scaling and discolouration were seen over the chest, anterior abdominal wall and both the thighs (Fig. 1). A clinical diagnosis of lobular panniculitis was made. His laboratory investigations such as blood counts, peripheral smear, bone marrow, and anti-nuclear antibody were unremarkable. Serum alkaline phosphatase and lactate dehydrogenase were elevated. One of the nodules was biopsied and sent for histopathlogical examination.

\section{Case 2}

A 44 year old male underwent excision biopsy of an indurated subcutaneous mass measuring $2 \times 2 \mathrm{~cm}$ in the right thigh, of one month duration. He had no organomegaly and his laboratory tests including a complete hemogram and bone marrow were within normal limits. 
On histopathological examination of the lesion on the thighs of both the patients showed a diffuse cellular infiltrate involving the septae and lobules of subcutaneous fat (Fig. 2) in a lobular panniculitis like pattern, sparing the overlying dermis and epidermis. The atypical lymphoid infiltrate was seen rimming the individual adipocytes in a lace like manner (Figs. 3, 4). These cells had pleomorphic, clefted nuclei with hyperchromasia and coarse chromatin. Interspersed amidst the neoplastic cells were karyorrhectic debris, mitotic figures and histiocytes. There was focal angiocentric distribution of the lymphomatous cells.
A diagnosis of SPTCL was made. On immunohistochemistry, the tumor cells were CD45 and CD3 positive (Figs. 5, 6) and negative for CD20 and CD30.

The patients received one cycle of CHOP (cyclophoshamide, vincristine, doxorubicin and prednisolone) regimen, which was well tolerated with healing of the cutaneous lesions. They were discharged on oral steroids and advised follow up after three weeks. The first patient continued to be in remission at the end of one year follow up. The second patient has not come again for review till date.

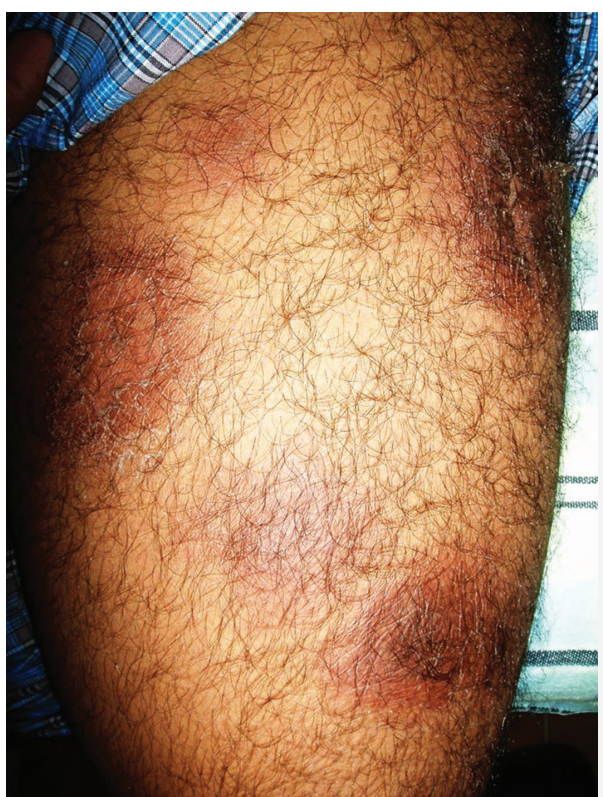

Figure 1. Multiple subcutaneous nodules involving the trunk and thighs with peripheral erythema and induration.

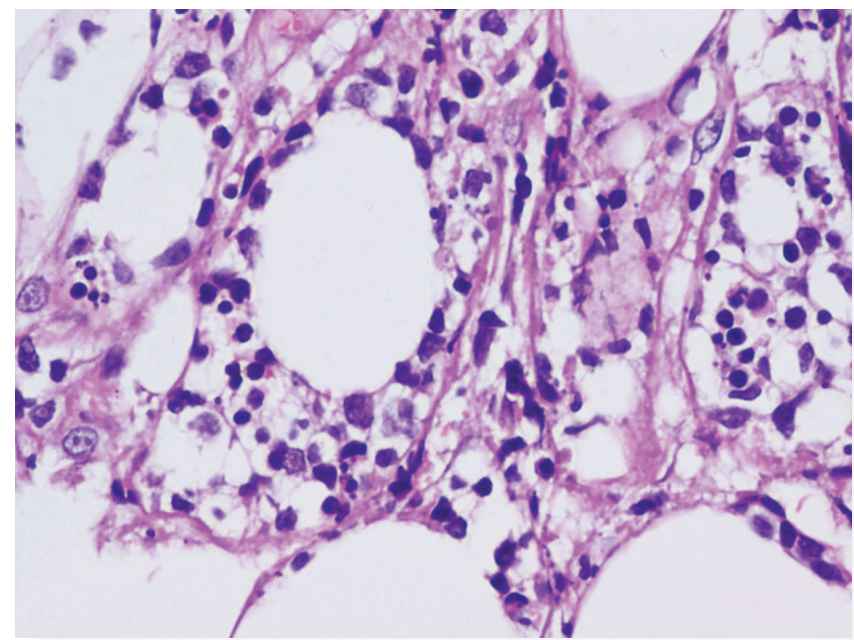

Figure 3. Higher magnification of the tumor in figure 2 demonstrated rimming of individual adipocytes by the neoplastic lymphoid cells. (Hematoxylin and Eosin stain, $\times 400)$

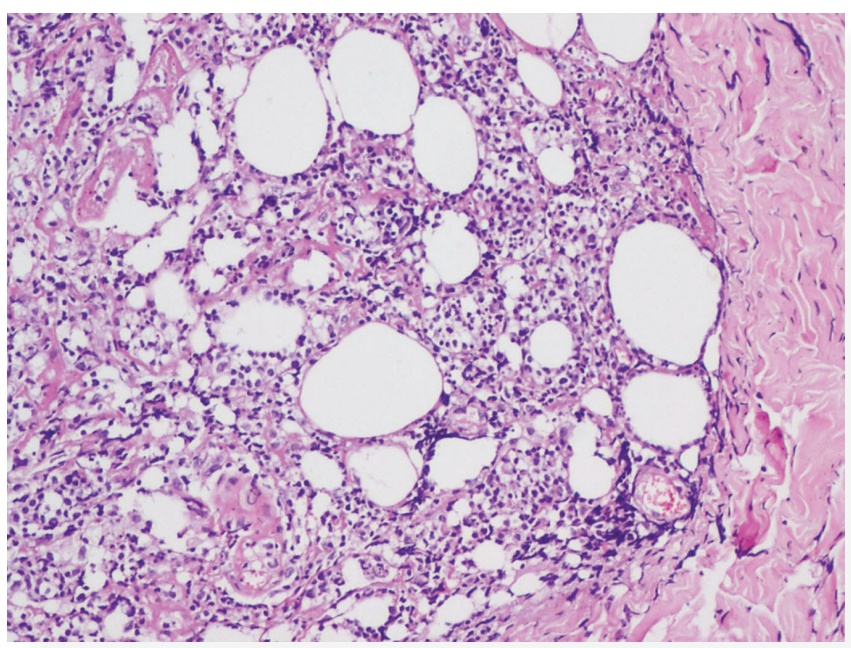

Figure 2. Histological examination revealed a diffuse cellular infiltrate of atypical lymphocytes involving the septae and lobules of subcutaneous fat in a lobular panniculitis like pattern. (Hematoxylin and Eosin stain, $x$ 100)

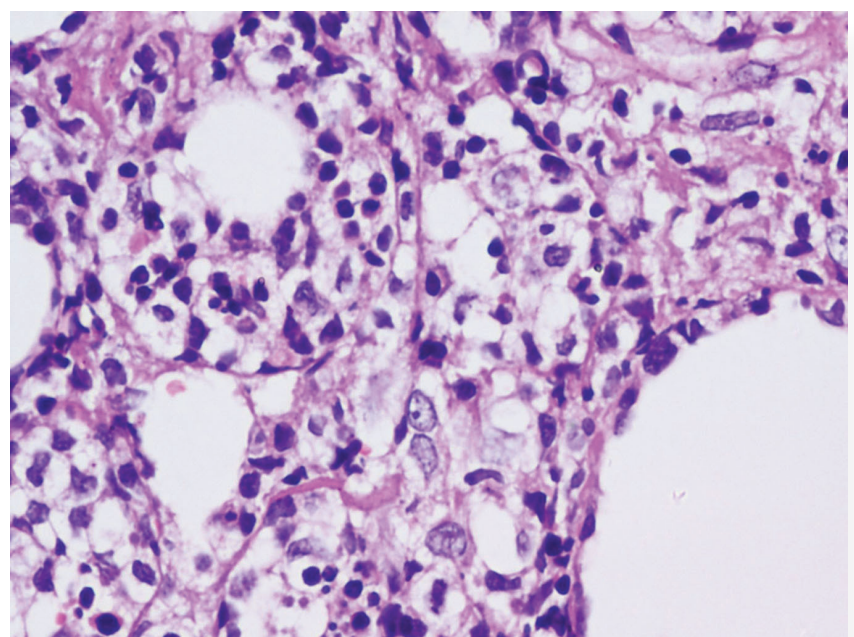

Figure 4. High power view of the neoplasm in figure 2 showed tumor cells with pleomorphic hyperchromatic nuclei, coarse chromatin and scanty cytoplasm. Interspersed amidst the neoplastic cells were karyorrhectic debris and histiocytes. (Hematoxylin and Eosin stain, $\times 400$ ) 


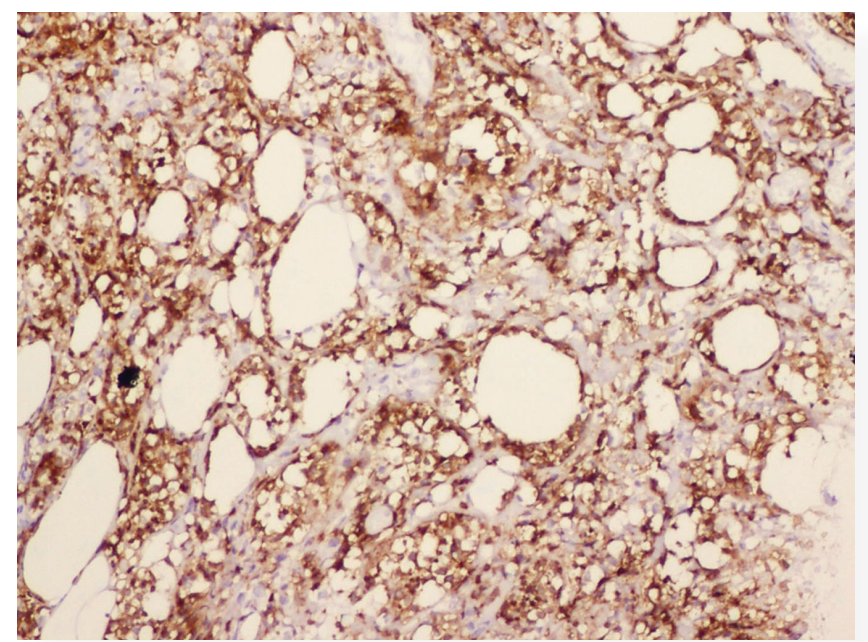

Figure 5. Immunohistochemistry showed the tumor cells were CD45 positive. $(\times 100)$

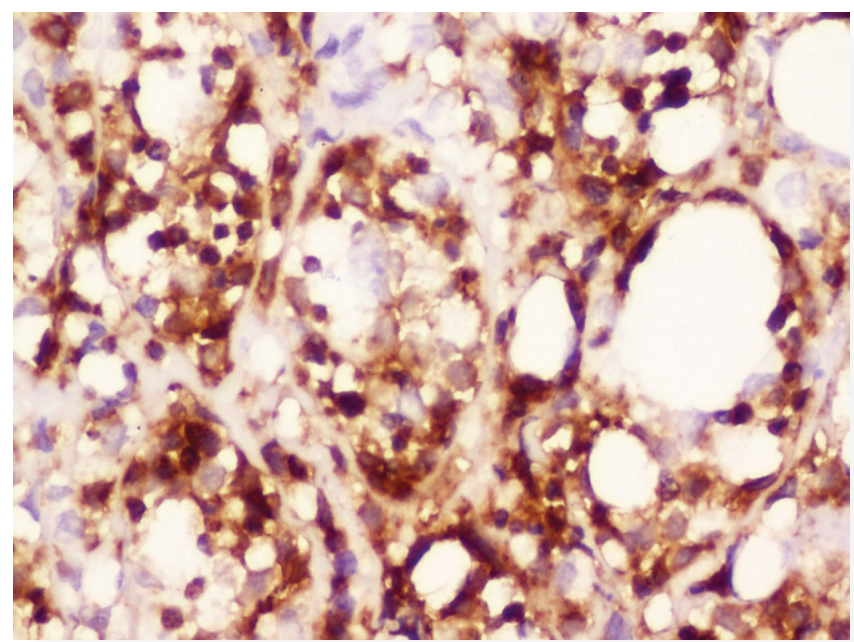

Figure 6. Immunohistochemistry revealed diffuse strong positivity of the tumor cells for CD3. $(\times 100)$

\section{Discussion}

Subcutaneous Panniculitis-like T-cell Lymphoma (SPTCL) is the least well defined and rarest subtype of PCL preferentially involving the subcutaneous fat that can clinically imitate panniculitis. It was defined as a distinct entity by the World Health Organization (WHO) classification in 2008 [3]. Lymphoma lesions consist of multiple subcutaneous swellings and/ or erythematous plaques or ulcerated skin nodules mostly located on the trunk, extremities and face.

Histologically the lymphoma infiltrate in SPTCL involves the lobules of the subcutaneous fat, resulting in a characteristic lobular panniculitis like pattern. Immunohistochemical studies have demonstrated that these atypical neoplastic lymphoid cells have a cytotoxic T-cell phenotype. The cells are consistently positive for CD3, CD45 and T-cell intracellular antigen (TIA1). Previously, two phenotypic subsets had been described based on T-cell receptor and CD56 expression [2-5]. SPTCL has a $\mathrm{CD}^{+}, \mathrm{CD}^{-}, \mathrm{CD}^{+}, \beta \mathrm{F} 1^{+}, \mathrm{TCR} \delta 1^{-}, \mathrm{CD}^{-} 6^{-}, \mathrm{CD} 30^{-}$phenotype and a favorable prognosis; while SPTCL $\gamma \delta$ or as per recent WHO classification Primary Cutaneous Gamma Delta T cell Lymphoma (PCGD-TC) have a $\mathrm{CD}^{+}, \mathrm{CD}^{-}, \mathrm{CD} 8{ }^{-}, \beta \mathrm{F} 1^{-}$, TCR $\delta 1^{+}, \mathrm{CD} 6^{+}, \mathrm{CD} 30^{+}$and a poor prognosis [2-7].

SPTCL lesions show only subcutaneous involvement by the mildly pleomorphic neoplastic lymphoid cells as was observed in our patients. There is moderate apoptosis and patchy necrosis. These features were noted in our cases also. In contrast, in PCGD-TCL though subcutaneous involvement is predominant there is infiltration of the overlying dermis or epidermis by the tumor cells. Angiocentric growth may be found. These cells are highly pleomorphic, show extensive apoptosis and areas of massive necrosis [4]. The immunophenotypical features of both have been enumerated above.

Patients with SPTCL type are usually young adults (median age, 36 years) presenting with subcutaneous nodules and erythematous plaques without ulceration [4]. Systemic manifestations such as fever, chills, night sweats and weight loss may be variably present and are usually mild. Cytopenias in the form of anemia, leucopenia, thrombocytopenia or combined can be seen to a mild degree in these patients. Individuals belonging to older age group (median age, 59 years), presenting with ulcerated nodules and disseminated plaques are likely to have the more aggressive PCGD-TC [4,5]. Systemic manifestations and cytopenias are more common and severe in these patients usually with a fatal outcome. Association with autoimmune disease is more common in SPTCL than PCGD-TC.

Distinguishing SPTCL from other types of cutaneous lymphomas is principally based on the subcutaneous localization of these lesions unlike the predominantly dermal involvement seen in mycosis fungoides, anaplastic large cell lymphoma, Natural Killer cell/ T-cell lymphoma [2-5,7,8]. Immunohistochemistry helps in clinching the diagnosis.

SPTCL must be differentiated from non-neoplastic panniculitis including lupus panniculitis. In benign panniculitis, CD20 ${ }^{+} \mathrm{B}$ cell aggregates are seen admixed with $\mathrm{CD}^{+}$cells containing equal proportion of $\mathrm{CD}^{+}$and $\mathrm{CD} 8+\mathrm{T}$ cells. The absence of malignant lymphocytes rimming individual fat cells classically seen in SPTCL and presence of reactive B- follicles with germinal centers admixed with plasma cells is indicative of lupus panniculitis $[4,7,8]$.

The treatment of SPTCL includes systemic steroids, multidrug chemotherapy, radiotherapy, and/ or bone marrow transplantation [4-7]. Since SPTCL behaves in an indolent manner, these patients can have long term remission with high dose systemic steroids. High dose chemotherapy and stem cell transplantation is usually considered in primary refractory or recurrent cases.[4,6] The response is variable but usually the prognosis is unfavorable in the presence of constitutional symptoms, cytopenia, multiple site involvement and associated haemophagocytic syndrome (HPS) $[6,9,10]$.

In conclusion, SPTCL represents a distinct clinicopathologic entity of clonal, cytotoxic T- cell lymphomas derived from $\alpha \beta$ $\mathrm{T}$ cells. SPTCL has a prolonged clinical course with recurrent panniculitis, is not commonly associated with HPS and rarely metastasize. The prognosis is favorable in SPTCL except in those cases associated with HPS. Awareness of this rare condition facilitates early diagnosis and appropriate management of these patients. 


\section{REFERENCES}

1. Gonzalez CL, Medeiros LJ, Braziel RM, Jaffe ES. T-cell lymphoma involving subcutaneous tissue: a clinicopathologic entity commonly associated with hemophagocytic syndrome. Am J Surg Pathol. 1991;15:17-27.

2. Goel K, Kini H, Rau AR, Nadar S, Pai MR, Rao HT. Cytomorphology of subcutaneous panniculitis-like T-cell lymphoma (SPTCL)- A case report. Indian J Pathol Microbiol. 2006;49:246-8. 3. Jaffe ES, Gaulard P, Ralfkiaer E, Cerroni L, Meijer CJLM. Subcutaneous panniculitis-like T-cell Lymphoma. In Swerdlow SH, Campo E, Harris NL, Jaffe ES, Pileri SA, Stein H, et al, eds. World Health Organization Classification of Tumours of Haematopoietic and Lymphoid Tissues. World Health Organization Classification of Tumors. 4th edn. Lyon, France: IARC Press,2008;294-5.

4. Willemze R, Jansen PM, Cerroni L, Berti E, Santucci M, Assaf C, et al. Subcutaneous Panniculitis-like T-cell Lymphoma: definition, classification and prognostic factors: an EORTC Cutaneous Lymphoma Group Study of 83 cases. Blood. 2008;111:838-45.

5. Bakhshi S, Das P, Puri K, Singhal M, Ramam M, Sharma A, et al. Subcutaneous panniculitis-like T-cell Lymphoma: Aclinicopathologic study of 5 cases. Indian J Pathol Microbiol. 2011;54:318-22.
6. Parveen Z, Thompson K. Subcutaneous Panniculitis-like T-cell Lymphoma. Redefinition of Diagnostic Criteria in the Recent World Health Organization- European Organization for Research and Treatment of Cancer Classification for Cutaneous Lymphomas. Arch Pathol Lab Med. 2009;133:303-8.

7. Paulli M, Berti E. Cutaneous T-cell lymphomas (including rare subtypes). Current concepts. II. Haematologica. 2004;89:1372-88.

8. Magro CM, Crowson AN, Kovatich AJ, Burns F. Lupus profundus, indeterminate lymphocytic lobular panniculitis and subcutaneous T-cell lymphoma: a spectrum of subcuticular T-cell lymphoid dyscrasia. J Cutan Pathol. 2001;28:235-47.

9. Go RS, Wester SM. Immunophenotypic and Molecular Features, Clinical Outcomes, Treatments, and Prognostic Factors Associated with Subcutaneous Panniculitis- like T-Cell Lymphoma. Cancer. 2004;101:1404-13.

10. Takeshita M, Imayama S, Oshiro Y, Kurihara K, Okamoto S, Matsuki Y, et al. Clinicopathologic Analysis of 22 cases of Subcutaneous Panniculitis-Like CD56- or CD56+ Lymphoma and Review of 44 Other Reported Cases. Am J Clin Pathol. 2004;121:40816.

Copyright by Jyoti Ramnath Kini, et al. This is an open access article distributed under the terms of the Creative Commons Attribution License, which permits unrestricted use, distribution, and reproduction in any medium, provided the original author and source are credited. 